\title{
Thermal stability of current gain in InGaP/GaAsSb/GaAs double-heterojunction bipolar transistors
}

\author{
B. P. Yan, ${ }^{\text {a) }}$ C. C. Hsu, X. Q. Wang, and E. S. Yang \\ Department of Electrical and Electronic Engineering, The University of Hong Kong, Pok Fu Lam Road, \\ Hong Kong SAR, People's Republic of China
}

(Received 6 July 2004; accepted 28 September 2004)

\begin{abstract}
The thermal stability of current gain in InGaP/GaAsSb/GaAs double-heterojunction bipolar transistors (DHBTs) is investigated. The experimental results show that the current gain in the InGaP/GaAsSb/GaAs DHBTs is nearly independent of the substrate temperature at collector current densities $>10 \mathrm{~A} / \mathrm{cm}^{2}$, indicating that the InGaP/GaAsSb/GaAs DHBTs have excellent thermal stability. This finding suggests that the InGaP/GaAsSb/GaAs DHBTs have larger emitter-base junction valence-band discontinuity than traditional GaAs-based HBTs. (C) 2004 American Institute of Physics. [DOI: 10.1063/1.1819505]
\end{abstract}

GaAs-based heterojunction bipolar transistors (HBTs) have been widely used for power amplifiers in wireless and high-speed digital applications. Compared with rival silicon bipolar and GaAs field-effect transistor devices, HBTs have several advantages, including high linearity, high transconductance, high power added efficiency, and low $1 / f$ noise. These advantages have made GaAs HBT the preferred technology for many military and commercial applications. However, GaAs HBTs have a relatively large base-emitter turn-on voltage due to the large band gap of GaAs used as the base layer, and this limits the minimum operating voltage and increases the power consumption in circuit applications. In addition, AlGaAs/GaAs HBTs suffer from current gain degradation at elevated temperature, which leads to a negative differential resistance and current collapse in $I-V$ curves. ${ }^{1,2}$ Although InGaP/GaAs HBTs have less temperature dependence on current gain than AlGaAs/GaAs HBTs, ${ }^{3}$ there is still observable gain degradation and negative differential resistance, especially for the semi-ordered InGaP/GaAs HBTs. ${ }^{4}$ The main reason for current gain degradation in GaAs-based HBTs is believed to be the low valence-band offset $\left(\Delta E_{V}\right)$ at the emitter-base (EB) heterojunction. ${ }^{3}$ In order to realize low-voltage, low-power and high reliable operation, it is essential to develop new GaAs-based HBTs with low turn-on voltage and better thermal stability. In terms of this requirement, future GaAs HBTs should use low energy band gap materials as the base layer to reduce the turn-on voltage. At the same time, the emitterbase junction should keep a large valence-band offset $\Delta E_{V}$, which would prevent the degradation of the current gain at elevated temperature.

Two different narrow band gap materials have been developed. The first is InGaAsN, which has been used as the base layer by several groups. ${ }^{5-8}$ However, InGaAsN material typically displays degraded minority carrier properties compared with GaAs, ${ }^{5,6}$ leading to the reduction of dc current gain and high frequency performance. Although these unfavorable characteristics can be suppressed by the insertion of graded layers between the base and collector junction, ${ }^{8}$ this complicates the transistor design and fabrication.

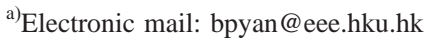

Another attractive narrow band gap base material is $\mathrm{GaAsSb}$, which has been used in InP/GaAsSb/InP HBTs by Bolognesi et $a .^{9,10}$ The lattice-matched InP/GaAsSb/InP HBT has demonstrated excellent high frequency and highspeed performance. However, GaAsSb as the base layer in the GaAs technology has had limited success because the materials are not lattice matched. Early work showed a poor current gain due to the use of a thick GaAsSb layer well above the critical layer thickness. ${ }^{11,12}$ Although the current gain could be improved by using a pseudomorphic GaAsSb layer as the base and a GaAs layer as the emitter, ${ }^{13}$ the devices showed a large recombination current at the GaAs emitter depletion region. Recently, we have developed a InGaP/GaAsSb/GaAs double-heterojunction bipolar transistor (DHBT) with low turn-on voltage and high current gain. ${ }^{14,15}$ By using a narrow-energy band gap GaAsSb layer as the base, the turn-on voltage of the device is reduced. The low turn-on voltage makes possible better power-added efficiency and lower operating voltage, which in turn allows the use of smaller and lighter batteries. This is of critical importance for any battery-operated device such as a cell phone. On the other hand, by using an InGaP layer as the emitter, the desirable band lineup at the emitter-base heterojunction is obtained, for the band gap offset at the InGaP/GaAsSb interface mainly appears on the valence band. ${ }^{14}$ This suggests that the blocking effect of $\Delta E_{V}$ on the base-to-emitter backinjection hole current would be more significant and, therefore, the InGaP/GaAsSb/GaAs DHBT is expected to have higher current gain and better thermal stability than traditional GaAs HBTs. In this letter, we study the temperature dependence of current gain of the $\mathrm{InGaP} / \mathrm{GaAsSb} / \mathrm{GaAs}$ DHBTs.

The InGaP/GaAsSb/GaAs DHBT structure was grown on a semi-insulating (100) GaAs substrate by metalorganic chemical vapor deposition. Trimethylgallium, trimethylindium, trimethylantimony, tertiarybutylphosphine, and tertiarybutylarsine were used as the organometallic sources. Carbon and silicon were used as $p$ - and $n$-type dopants, respectively. The device nominal structure consists of a $500 \mathrm{~nm}$ GaAs subcollector $\left(n>3 \times 10^{18} \mathrm{~cm}^{-3}\right)$, a $500 \mathrm{~nm}$ GaAs collector $\left(n=5 \times 10^{16} \mathrm{~cm}^{-3}\right)$, a $50 \mathrm{~nm} \mathrm{GaAsSb}$ base ( Sb composition $=10.4 \%, p=8 \times 10^{18} \mathrm{~cm}^{-3}$ ), a $50 \mathrm{~nm} \mathrm{InGaP}$ emitter $\left(n=3 \times 10^{17} \mathrm{~cm}^{-3}\right)$, a $150 \mathrm{~nm}$ GaAs layer $(n=4$ 


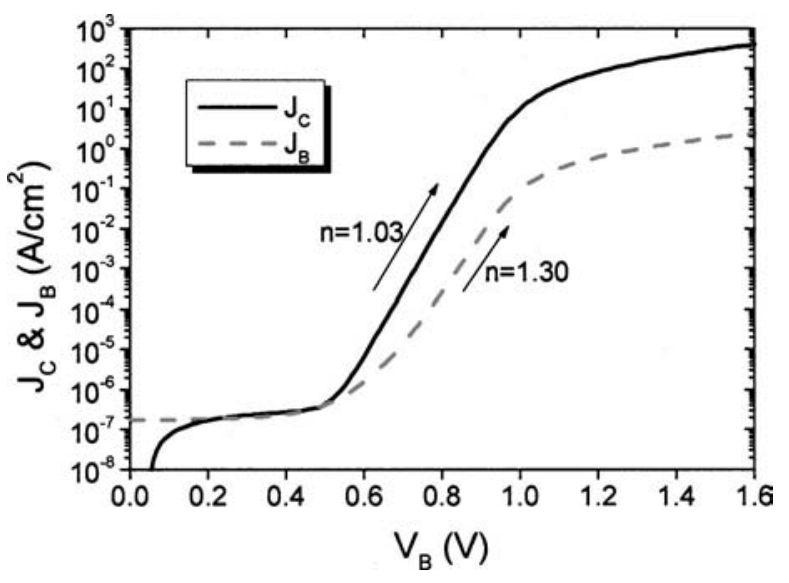

FIG. 1. (Color online) Representative Gummel plots for InGaP/GaAsSb/GaAs DHBT with an emitter area of $100 \times 100 \mu \mathrm{m}^{2}$.

$\left.\times 10^{18} \mathrm{~cm}^{-3}\right), \quad$ a $\quad 50 \mathrm{~nm}$ compositionally graded $\operatorname{In}_{x} \mathrm{GaAs}_{1-x}$ cap layer $\left(x=0-0.5, n>1 \times 10^{19} \mathrm{~cm}^{-3}\right)$ and a $50 \mathrm{~nm} \quad \operatorname{In}_{0.5} \mathrm{GaAs}_{0.5}$ cap ohmic contact layer $(n>1$ $\times 10^{19} \mathrm{~cm}^{-3}$ ). The $\mathrm{Sb}$ composition was confirmed by highresolution $\mathrm{x}$-ray diffraction measurement. The surface morphology was observed by atomic force microscope and no cross-hatched patterns associated with misfit dislocations were observed. This suggests that the GaAsSb base layer is fully strained. The structure was fabricated into devices using optical lithography and chemical wet selective etching for mesa definition.

Figure 1 shows the Gummel plots of a large area device of $100 \times 100 \mu \mathrm{m}^{2}$. The device demonstrates a current gain greater than unity at ultra-small collector current density of $1 \times 10^{-6} \mathrm{~A} / \mathrm{cm}^{2}$. The device also displays a low turn-on voltage, $0.914 \mathrm{~V}$, at $J_{C}=1 \mathrm{~A} / \mathrm{cm}^{2}$, which is $0.18 \mathrm{~V}$ lower than that of conventional InGaP/GaAs HBTs. ${ }^{15}$ Measured Gummel plots are near-ideal. The ideality factor of the collector current is 1.03 . The base current has different ideality factors depending on the current level. The ideality factor of base current is near 2.0 at the low current level. At high current level, the ideality factor is 1.30. In comparison with GaAs/GaAsSb/GaAs DHBT, ${ }^{13}$ the recombination current of $\mathrm{InGaP} / \mathrm{GaAsSb} / \mathrm{GaAs} \mathrm{DHBT}$ is greatly reduced due to the use of InGaP as emitter layer instead of GaAs.

Figure 2 illustrates the measured current gain as a func-

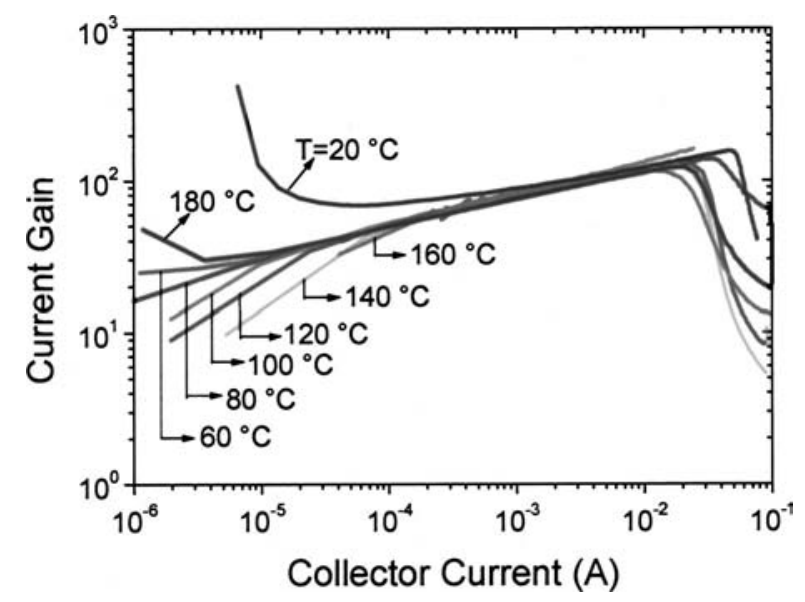

FIG. 2. (Color online) Measured current gain vs collector current of

InGaP/GaAsSb/GaAs DHBT at different substrate temperatures. peratures keep constant even at the small current of 0.1 mA.
Downloaded 08 Nov 2006 to 147.8.21.97. Redistribution subject to AlP license or copyright, see http://apl.aip.org/apl/copyright.jsp

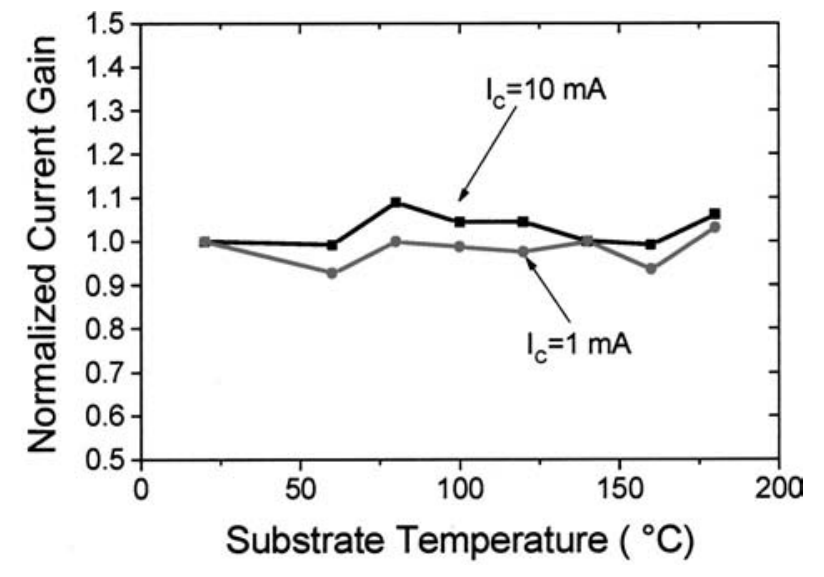

FIG. 3. (Color online) Normalized current gain vs substrate temperature for the $\mathrm{InGaP} / \mathrm{GaAsSb} / \mathrm{GaAs}$ DHBTs at collector current of 1 and $10 \mathrm{~mA}$.

tion of collector current for a InGaP/GaAsSb/GaAs DHBT with emitter size of $100 \times 100 \mu \mathrm{m}^{2}$, as the substrate temperature was varied from 20 to $180{ }^{\circ} \mathrm{C}$. It can be seen that, at current densities $J_{C}>10 \mathrm{~A} / \mathrm{cm}^{2}$, the measured current gains nearly overlap for different substrate temperature, indicating that the current gain of the DHBTs is basically independent of temperature. For clarity, Fig. 3 shows the current gain, normalized by its value at room temperature, as a function of the substrate temperature at collector current of 1 and $10 \mathrm{~mA}$, respectively. The current gain at $180{ }^{\circ} \mathrm{C}$ varies only $3 \%$ for $J_{C}$ of $10 \mathrm{~A} / \mathrm{cm}^{2}$, and $6 \%$ for a $J_{C}$ of $100 \mathrm{~A} / \mathrm{cm}^{2}$. This result is significantly different from that of the conventional $\mathrm{AlGaAs} / \mathrm{GaAs}^{3}$ and semi-ordered InGaP/GaAs $\mathrm{HBTs}^{4}$ in which the current gain degrades with the increase of temperature. The excellent thermal stability of current gain in the $\mathrm{InGaP} / \mathrm{GaAsSb} / \mathrm{GaAs} \mathrm{DHBT}$ is attributed to the band alignment particular to the InGaP/GaAsSb heterojunction. In general, the decrease of the current gain with temperature depends on the valence band discontinuity $\left(\Delta E_{V}\right)$ of the base-emitter heterojunction. For traditional AlGaAs/GaAs and InGaP/GaAs HBTs, the valence band discontinuity at the EB heterojunction was estimated to be $0.19^{16}$ and $0.43 \mathrm{eV},{ }^{17}$ respectively. When $\mathrm{Sb}$ composition is incorporated into GaAs base, the energy band gap of the base material is reduced. ${ }^{13,14}$ The band gap reduction depends on incorporated $\mathrm{Sb}$ composition. For $10.4 \% \mathrm{Sb}$ composition, calculated band gap reduction is about $0.186 \mathrm{eV}$. Thus the total valence discontinuity at the $\mathrm{InGaP} / \mathrm{GaAsSb}$ heterojunction should be the sum of 0.43 and $0.186 \mathrm{eV}$, i.e., $0.616 \mathrm{eV}$. That means that the valence discontinuity in the InGaP/GaAsSb heterojunction is much larger than that in traditional $\mathrm{AlGaAs} / \mathrm{GaAs}$ and $\mathrm{InGaP} / \mathrm{GaAs}$ heterojunction. The larger the valence band discontinuity, the more remarkable the blocking effect on the base-to-emitter backinjection holes. Therefore, the current gain of the InGaP/GaAsSb/GaAs DHBT exhibits better thermal stability than traditional GaAs-based HBTs. On the other hand, the base sheet resistance also influences the thermal stability of the current gain. The base sheet resistance was measured as $8300 \Omega /$ sq using transmission-line patterns. Although it is large relative to that of traditional GaAs base, the influence of it on thermal stability of the current gain is not significant compared with the contribution from band alignment, because the current gains measured at different substrate temperatures keep constant even at the small current of $0.1 \mathrm{~mA}$.
AlP license or copyright, see http://apl.aip.org/apl/copyright.jsp 
The independence of the current gain on the temperature is favorable to power devices. It is well known that there are two thermal phenomena in power HBTs, i.e., thermal runaway and the collector current collapse, which are caused by current crowding effect. When the current crowding effect exists in a device, the temperature dependence can provide an electrical-thermal positive feedback loop that gives rise to thermal runaway for a positive current gain coefficient and current collapse for a negative current gain coefficient. If, however, the current gain is independent of temperature, there will not be a feedback mechanism to produce a catastrophic effect. Therefore, from the point of view of thermal management, the InGaP/GaAsSb/GaAs DHBT should have greater potential for power application.

In summary, we studied the thermal stability of current gain in the InGaP/GaAsSb/GaAs DHBTs. The experimental results show that the current gain in the $\mathrm{InGaP} / \mathrm{GaAsSb} / \mathrm{GaAs}$ DHBTs is nearly independent of the substrate temperature at collector current densities $>10 \mathrm{~A} / \mathrm{cm}^{2}$, which indicates that the $\mathrm{InGaP} / \mathrm{GaAsSb} / \mathrm{GaAs}$ DHBTs have excellent thermal stability. This finding suggests that the InGaP/GaAsSb/GaAs DHBTs have larger emitter-base junction valence-band discontinuity than traditional GaAs-based HBTs.

The authors would like to thank the support of Research Grants Council of Hong Kong Special Administrative Region, China (Project No. HKU7069/02E).
${ }^{1}$ G. B. Gao, H. Morkoc, and M. F. Chang, IEEE Trans. Electron Devices 39, 1987 (1992).

${ }^{2}$ W. Liu, S. Nelson, D. Hill, and A. Khatibzadeh, IEEE Trans. Electron Devices 40, 1917 (1993).

${ }^{3}$ W. Liu, S. K. Fan, T. Henderson, and D. Davito, IEEE Trans. Electron Devices 40, 1351 (1993).

${ }^{4}$ W. Liu, E. Beam, III, T. Kim, and A. Khatibzadeh, in Current Trends in Heterojunction Bipolar Transistors, edited by M. F. Chang (World Scientific, Singapore, 1996), pp. 241-301.

${ }^{5}$ R. J. Welty, H. P. Xin, K. Mochizuki, C. W. Tu, and P. M. Asbeck, SolidState Electron. 46, 1 (2002).

${ }^{6}$ P. C. Chang, C. Monier, A. G. Baca, N. Y. Li, F. Newman, E. Armour, and H. Q. Hou, Solid-State Electron. 46, 581 (2002).

${ }^{7}$ R. E. Welser, P. M. DeLuca, and N. Pan, IEEE Electron Device Lett. 21, 554 (2000).

${ }^{8}$ P. M. DeLuca, C. R. Lutz, R. E. Welser, T. Y. Chi, E. K. Huang, R. J. Welty, and P. M. Asbeck, IEEE Electron Device Lett. 23, 582 (2002).

${ }^{9}$ C. R. Bolognesi, N. Matine, M. W. Dvorak, P. Yeo, X. G. Xu, and S. P. Watkins, IEEE Trans. Electron Devices 48, 2631 (2001).

${ }^{10}$ M. W. Dvorak, C. R. Bolognesi, O. J. Pitts, and S. P. Watkins, IEEE Electron Device Lett. 22, 361 (2001).

${ }^{11}$ B. Khamsehpour and K. E. Singer, Electron. Lett. 26, 965 (1990).

${ }^{12}$ K. Ikossi-Anastasiou, IEEE Trans. Electron Devices 40, 878 (1993).

${ }^{13}$ T. Oka, T. Mishima, and M. Kudo, Appl. Phys. Lett. 78, 483 (2001).

${ }^{14}$ B. P. Yan, C. C. Hsu, X. Q. Wang, and E. S. Yang, IEEE Electron Device Lett. 23, 170 (2002).

${ }^{15}$ B. P. Yan, C. C. Hsu, X. Q. Wang, and E. S. Yang, in 14th Indium Phosphide and Related Materials Conference (IEEE, Stockholm, 2002), pp. 169-172.

${ }^{16}$ J. Batey and S. L. Wright, J. Appl. Phys. 59, 200 (1986).

${ }^{17}$ T. Kobayashi, K. Taira, F. Nakamura, and H. Kawai, J. Appl. Phys. 65, 4898 (1989). 